\title{
Specifics of the impact of les mills fitness programs on the women's physical fitness of $30-35$ years of different somatotypes
}

Natalia Romanenko, Victoria Sudar ${ }^{*}$, Victoria Raspopova, Elizabeth Yurkina, Anastasia Ostapchuk Kuban State University of Physical Culture, Sports and Tourism, 350015, Krasnodar, Russia

\begin{abstract}
At present, the increasing role of women in all areas of modern society is obvious. In this regard, the issue of preserving their health in the circumstances of a negative environmental situation, the intensification and computerization of labor activity is important and actual. Regular physical activity based on health-improving physical culture helps to improve the physical condition of women. There are some shortcomings in the physical education organization for women of the first Mature age. It leads to a lack of systematic growth in physical fitness indicators, and a decrease in motivation for physical education. It is important to find effective ways to improve the physical training of the first Mature age women and evaluate the effectiveness of various motor activity types. The article discusses the characteristics and influence of fitness programs in the Les Mills direction on the development of women physical qualities, taking into account different somatotypes. The results of the study made it possible to determine the somatotype according to the metric scheme of R. N. Dorokhov, body components, their severity and ratio, the physical capabilities of women 30-35 years old, depending on their somatic characteristics. In order to increase the level of physical fitness for each somatotype of women, fitness programs were selected based on the popular Les Mills direction. As a result of the study, the effectiveness of combining fitness tools that help increase the physical capabilities of women 30-35 years old with various somatotypic parameters was proved.
\end{abstract}

\section{Introduction}

An active lifestyle is a valuable resource for a person's physical condition, but according to the health workers' conclusion, it is low and cause the life quality decrease, and a number of different diseases. Lack of motor activity leads to functional capabilities decline. It generally affects the performance of the body as a whole [11, 12].

Currently, experts observe an insufficient level of population physical fitness, associated with the growth of technological progress. It makes person's life comfortable and sedentary, and increasing of mental and psychoemotional loads $[8-10,13]$. This is especially true for women of the first period of adulthood who perform the main biological function-motherhood and care for the children's upbringing. With a small amount of free time, the issue of attracting women to sports and recreation activities is particularly acute.

The fitness system is most popular among women, especially the Les Mills fitness programs. They came to Russia from Australia. These programs develop physical qualities and functional capabilities of the body [3]. However, according to some experts, the morphological criterion of the Constitution-somatotype, combined with functional characteristics, features of the organization of metabolism, and motor capabilities - is not always taken into account when constructing physical culture and health classes [1, 5, 14]. During sports selection, adaptation to physical activity, physique features are taken into account (body proportions, body composition, somatotype), the relationship between morphological and functional features is studied. In health-improving physical culture such studies are not systematic, and the literature data often contradict each other. That's why, conducting a study related to the improving the effectiveness of women's physical education, differentiated depending on the somatotype, based on fitness tools, seems relevant.

\section{Materials and methods}

The women's physical condition of the first Mature age depends on many factors, among which the most important are the lifestyle and systematic exercise $[6,7]$.

According to morphology specialists, it is necessary to take into account the somatic status of women. It is understood from the Greek (soma - body) and Latin (status - state) features of the physique [1, 4]. Its need for effective physical training management.

\footnotetext{
* Corresponding author: unona-vvs@ mail.ru
} 
The research was conducted in the city of Krasnodar, Russia on the basis of the fitness center "Fit Line" and fitness club "Forma" for 6 months in the period from October 2019 to March 2020. 70 women 30-35 years old engaged in health fitness were under observation.

The preliminary research made it possible to determine the somatotype along the line of dimensional (nanomegalosomal) variation according to the metric scheme of R. N. Dorokhov [2]. The majority of women belong to the mesosomal type $-42.9 \%, 31.3 \%$ - to the macrosomal type, and the smallest part to the microsomal type- $25.8 \%$.

For an adequate selection of fitness tools, it was necessary to determine the body components, their severity and ratio. So weak development of fat and lean body mass and low bone component identified microsomnia type women, secondary development have mezosomnia type women, high values have macrosomnia type women. So microsomatics have a low level of endurance and strength development, mesosomatics have weak coordinating abilities, and microsomatic have not enough flexibility and joint mobility.

Participants of the experiment were divided into 2 groups of 35 people. Each of them was divided into three subgroups, taking into account the somatotype: microsomal (MIS), mesosomal (MES) and macrosomal (MAS). Women in the control group performed aerobic and strength-oriented exercises. The experimental group women attend fitness programs of the Les Mills direction.

Women microsomatic type $(n=9)$ engaged in a Pump Body based on repeting method with different weights, and RPM intensive class cycle training on stationary bikes. Women mesosomal type $(n=16)$ was offered a fitness program Body Step Classic, based on the speed and rhythm exercise using a step platform and Plyometrics weights and GRIT - intensive exercises with the own weight on the power endurance development. Women macrosomal type $(n=10)$ - CXWorx - intensive training aimed at working out all the main muscle groups, especially the strength of the core muscles and Body Balance-a combination of elements of yoga, Pilates and stretching. Both groups worked out 4 times a week for 50-60 minutes.

\section{Results and discussion}

At the beginning of the pedagogical experiment, there were no significant differences between the two groups in terms of physical fitness. After six months of training, a comparative analysis of each physical quality revealed significant differences in absolute indicators, as well as in the growth rate of the studied parameters. The use of intensive training for the development of strength endurance CXWorx allowed macrosomic women in experimental group to significantly $(\mathrm{p}<0.001)$ improve the result in the $1000 \mathrm{~m}$ run by 15.5 seconds, the growth rate was $4.8 \%$. Significant $(\mathrm{p}<0.001)$ values were also achieved by women of microsomal type engaged in cycle training, improving their performance by 12.2 seconds, the growth rate was 3.8\%. Combining the programs Body Step Classic and GRIT Plyometrics performed with their own body weight at a fast pace, helped to increase endurance in representatives of the mesosomal type, who improved their performance by 3.1 seconds, the growth rate was $3.6 \%$. the Data are presented in table 1.

Table 1. Physical fitness indicators of women 30-35 years old in the experimental group

\begin{tabular}{|c|c|c|c|c|c|c|}
\hline Test & Somatotype & $\begin{array}{l}\text { October } \\
\mathrm{M} \pm \mathrm{m}\end{array}$ & $\begin{array}{l}\text { March } \\
\mathrm{M} \pm \mathrm{m}\end{array}$ & $\mathrm{t}$ & $\mathrm{P}$ & $\Delta, \%$ \\
\hline \multirow[t]{3}{*}{ Running $1000 \mathrm{~m}, \mathrm{~s}$} & Mis & $371,7 \pm 2,29$ & $359,5 \pm 2,14$ & 4,12 & $<0,001$ & 3,1 \\
\hline & Mes & $369,6 \pm 3,29$ & $356,9 \pm 1,61$ & 3,73 & $<0,001$ & 3,7 \\
\hline & Mas & $372,1 \pm 3,10$ & $356,6 \pm 2,50$ & 3,95 & $<0,001$ & 4,4 \\
\hline \multirow{3}{*}{$\begin{array}{l}\text { High crossbar } \\
\text { hanging, } s\end{array}$} & Mis & $8,2 \pm 0,30$ & $9,7 \pm 0,27$ & 4,35 & $<0,001$ & 19,2 \\
\hline & Mes & $9,5 \pm 0,28$ & $11,4 \pm 0,24$ & 4,62 & $<0,001$ & 16,3 \\
\hline & Mas & $8,3 \pm 0,27$ & $10,2 \pm 0,27$ & 4,96 & $<0,001$ & 14,4 \\
\hline \multirow{3}{*}{$\begin{array}{l}\text { Arm-pumping } \\
\text { exercises, number } \\
\text { of times }\end{array}$} & Mis & $10,6 \pm 0,50$ & $12,7 \pm 0,34$ & 3,76 & $<0,001$ & 15,6 \\
\hline & Mes & $10,9 \pm 0,32$ & $12,3 \pm 0,26$ & 3,55 & $<0,01$ & 12,6 \\
\hline & Mas & $10,4 \pm 0,29$ & $11,7 \pm 0,38$ & 4,14 & $<0,001$ & 17,8 \\
\hline \multirow{3}{*}{$\begin{array}{l}\text { Lifting the torso, } \\
\text { number of times }\end{array}$} & Mis & $11,5 \pm 0,61$ & $14,2 \pm 0,28$ & 3,42 & $<0,01$ & 18,5 \\
\hline & Mes & $11,6 \pm 0,30$ & $13,4 \pm 0,40$ & 3,67 & $<0,001$ & 16,4 \\
\hline & Mas & $10,9 \pm 0,48$ & $13,2 \pm 0,53$ & 3,13 & $<0,001$ & 19,1 \\
\hline \multirow{3}{*}{$\begin{array}{l}\text { Long jump from a } \\
\text { standstill, } \mathrm{cm}\end{array}$} & Mis & $122,3 \pm 0,85$ & $127,2 \pm 1,08$ & 3,39 & $<0,05$ & 3,7 \\
\hline & Mes & $120,8 \pm 0,52$ & $124,6 \pm 0,97$ & 3,52 & $<0,001$ & 3,2 \\
\hline & Mas & $122,7 \pm 0,74$ & $127,8 \pm 1,02$ & 3,86 & $<0,01$ & 3,9 \\
\hline \multirow{3}{*}{$\begin{array}{c}\text { A forward bend } \\
\text { while standing, } \mathrm{cm}\end{array}$} & Mis & $6,9 \pm 0,32$ & $8,4 \pm 0,33$ & 2,62 & $<0,05$ & 15,7 \\
\hline & Mes & $6,7 \pm 0,21$ & $8,3 \pm 0,19$ & 4,33 & $<0,001$ & 16,5 \\
\hline & Mas & $7,3 \pm 0,29$ & $8,5 \pm 0,23$ & 3,13 & $<0,01$ & 15,2 \\
\hline \multirow{3}{*}{$\begin{array}{l}\text { Hand twisting in the } \\
\text { shoulder joints, } \mathrm{cm}\end{array}$} & Mis & $113,2 \pm 3,16$ & $102,7 \pm 1,81$ & 3,15 & $<0,001$ & 10,4 \\
\hline & Mes & $114,6 \pm 2,15$ & $100,9 \pm 2,12$ & 4,43 & $<0,001$ & 12,3 \\
\hline & Mas & $117,2 \pm 2,72$ & $102,5 \pm 1,81$ & 4,59 & $<0,001$ & 9,7 \\
\hline
\end{tabular}

Women in the control group also significantly $(\mathrm{p}<0.05)$ improved their results. However, their absolute values and growth rates were significantly lower than in the experimental group. Representatives of the MIS type improved by 
5.8 seconds, an increase of $2.6 \%$, MES type - by 2.9 seconds and MAS type by 4.2 seconds, the growth rates were 1.6 and $2.7 \%$. The data is presented in table 2 .

Table 2. Physical fitness indicators of women 30-35 years old in the control group.

\begin{tabular}{|c|c|c|c|c|c|c|}
\hline \multirow{2}{*}{ Тест } & $\begin{array}{c}\text { Somatotyp } \\
\text { es }\end{array}$ & $\begin{array}{c}\text { October } \\
\mathrm{M} \pm \mathrm{m}\end{array}$ & $\begin{array}{c}\text { March } \\
\mathrm{M} \pm \mathrm{m}\end{array}$ & $\mathrm{t}$ & $\mathrm{P}$ & $\Delta, \%$ \\
\hline \multirow{4}{*}{ Running $1000 \mathrm{~m}, \mathrm{~s}$} & Mis & $373,3 \pm 2,04$ & $367,5 \pm 1,03$ & 2,34 & $<0,05$ & 2,3 \\
\cline { 2 - 7 } & Mes & $365,7 \pm 1,99$ & $362,8 \pm 2,96$ & 2,12 & $<0,05$ & 2,2 \\
\cline { 2 - 7 } & Mas & $371,5 \pm 3,39$ & $367,3 \pm 1,01$ & 2,14 & $<0,05$ & 2,2 \\
\hline \multirow{2}{*}{$\begin{array}{c}\text { High crossbar hanging, } \\
\text { s }\end{array}$} & Mis & $7,5 \pm 0,27$ & $8,1 \pm 0,37$ & 1,30 & $>0,05$ & 1,5 \\
\cline { 2 - 7 } & Mes & $9,2 \pm 0,29$ & $9,9 \pm 0,21$ & 2,14 & $<0,05$ & 8,1 \\
\cline { 2 - 7 } & Mas & $7,5 \pm 0,32$ & $8,3 \pm 0,27$ & 1,74 & $>0,05$ & 9,2 \\
\hline \multirow{2}{*}{$\begin{array}{c}\text { Arm-pumping } \\
\text { exercises, number of } \\
\text { times }\end{array}$} & Mis & $9,7 \pm 0,55$ & $10,8 \pm 0,47$ & 1,79 & $>0,05$ & 12,6 \\
\cline { 2 - 7 } & Mes & $10,5 \pm 0,29$ & $11,2 \pm 0,24$ & 1,75 & $>0,05$ & 6,2 \\
\hline \multirow{2}{*}{$\begin{array}{c}\text { Lifting the torso, } \\
\text { number of times }\end{array}$} & Mas & $9,7 \pm 0,27$ & $10,6 \pm 0,56$ & 1,29 & $>0,05$ & 8,2 \\
\cline { 2 - 7 } & Mis & $11,6 \pm 0,57$ & $12,8 \pm 0,60$ & 2,15 & $<0,05$ & 15,1 \\
\cline { 2 - 7 } & Mes & $12,1 \pm 0,28$ & $12,7 \pm 0,26$ & 2,22 & $<0,05$ & 6,7 \\
\hline \multirow{2}{*}{$\begin{array}{c}\text { Long jump from a } \\
\text { standstill, cm }\end{array}$} & Mis & $10,5 \pm 0,38$ & $11,7 \pm 0,27$ & 2,12 & $<0,05$ & 8,8 \\
\cline { 2 - 7 } & Mes & $11,2 \pm 0,94$ & $123,7 \pm 0,82$ & 2,14 & $<0,05$ & 2,2 \\
\cline { 2 - 7 } & Mas & $121,2 \pm 1,09$ & $121,4 \pm 1,15$ & 2,07 & $<0,05$ & 2,4 \\
\hline \multirow{2}{*}{$\begin{array}{c}\text { A forward bend while } \\
\text { standing, cm }\end{array}$} & Mis & $6,2 \pm 0,26$ & $124,5 \pm 1,14$ & 2,13 & $<0,05$ & 2,6 \\
\cline { 2 - 7 } & Mes & $6,7 \pm 0,20$ & $7,1 \pm 0,32$ & 2,24 & $<0,05$ & 14,3 \\
\cline { 2 - 7 } & Mas & $6,8 \pm 0,32$ & $7,5 \pm 0,19$ & 2,08 & $<0,05$ & 8,2 \\
\hline \multirow{2}{*}{$\begin{array}{c}\text { Hand twisting in the } \\
\text { shoulder joints, cm }\end{array}$} & Mis & $111,6 \pm 3,17$ & $10,8 \pm 0,39$ & 1,94 & $>0,05$ & 13,3 \\
\cline { 2 - 7 } & Mes & $112,2 \pm 2,20$ & $109,6 \pm 2,68$ & 0,85 & $>0,05$ & 3,1 \\
\cline { 2 - 7 } & Mas & $114,2 \pm 2,97$ & $110,6 \pm 2,96$ & 0,83 & $>0,05$ & 2,1 \\
\hline
\end{tabular}

The use of a multi-repeat method of performing strength exercises with a mini barbell allowed microsomatic women to increase $(\mathrm{p}<0.001)$ the strength of the shoulder girdle and back muscles evaluated by the " the crossbar hanging" test. The growth rate was $19.4 \%$. In MES and MAS -16.3 and 14.4\%, respectively. In the control group, significant $(\mathrm{p}<0.05)$ changes were found only in representatives of the MES type- $8.1 \%$.

In the test "arm-pumping exercises in laying position", significant $(\mathrm{p}<0.01-0.001)$ differences were found in all subgroups of the experimental group. The highest growth rates in the strength assessment of the shoulder girdle and chest muscles were found in women of the macrosomal type $17.6 \%$. No significant differences were found in the control group ( $\mathrm{p}>0.05)$.

The greatest results in the test "lifting the torso" were achieved by women macrosomatics from the experimental group. Their intensive training was aimed at working out all the main muscle groups, especially the strength of the cortex muscles. The growth rate was $19.6 \%$, while their peers from the control group $-9.1 \%$.

The dynamic strength of the leg muscles was significantly higher in the experimental group than in the control group. the leading position was taken by macrosomatics with a growth rate of $3.9 \%$.

Performing exercises of the GRIT Plyometrics fitness program allowed mesosomal women to significantly $(\mathrm{p}<0.001)$ improve their results in the tests of standing forward tilt and hand scrolling by $16.5 \%$ and $12.3 \%$, respectively. A similar pattern was found in microsomatics (15.9-10.3\%) and macrosomatics engaged in Body Balance based on elements of yoga, Pilates and stretching (5.2-9.9\%).

\section{Conclusions}

The results of the comparative analysis clearly show that the formation of groups based on somatotypological characteristics and an adequate combination of fitness programs from the Les Mills direction for women of the microsomal type (with weakly expressed muscle mass)-strength training Body Pump with mini barbells and RPM cycle training intensive training on stationary bicycles, for mesosomal (with an average level of fat and different muscle mass) - interval training Body Step Classic and GRIT Plyometrics, for macrosomal (with increased body fat and muscle mass) CXWorx - intensive training aimed at working out all the main muscle groups, especially the strength of the core muscles and Body Balance (elements of yoga, Pilates, stretching) leads to an increase in the physical fitness level of women 30-35 years old compared to the traditional approach.

\section{References}

1. G.I. Deryabina, A.N. Novikova, Bulletin of Tambov University. Series: Humanitarian Sciences, 10(14), $203-207$ (2012)

2. A.S. Kuznetsov, Z.M. Kuznetsova, Russian Journal of Physical Education and Sport, 14(4), 5-7 (2019)

3. N.G. Lutchenko, N.I. Perevoznikova, V.G. Ivanov, Journal: Problems of modern pedagogical education, 55-5, 171-177 (2017) 
4. D.B. Nikityuk, S.V. Klochkova, E.A. Rozhkova, I.V. Pogonchenkova, E.A. Turova, Questions of balneology, physiotherapy, and therapeutic physical culture, 96(2-2), 121 (2019)

5. N.I. Romanenko, Methods of physical education of Mature women with the use of health-improving physical culture (based on somatotype): educational and methodological guide (KSUFKST, Krasnodar, 2017)

6. N.I. Romanenko, Scientific and methodological journal "Physical culture, sport-science and practice", 1(March), 52-56 (2018)

7. N.I. Romanenko, E.V. Klochko, Actual problems of physical culture and sports in modern socio-economic conditions: materials of the international journal. scientific-practical Conf., may 20, 2019 (Chuvash State Agricultural Academy, Cheboksary, 172-177, 2019)

8. S.V. Savin, O.N. Stepanova, Pedagogical design of fitness classes with adults (MPSU, M., 2015)

9. V.V. Sudar, Humanities and natural science: problems, ideas, innovations: Materials of the all-Russian scientific and practical conference with international participation. Chistopol, September 27, 2019 (Astor and Ya Printing Company, Kazan, 150-153, 2019)

10. I.G. Kalina, A.I. Golubev, R.A. Aidarov, Journal of Organizational Culture, Communications and Conflict, 20(3), 89-94 (2016)

11. E.V. Lyubina, L.B. Andryushchenko, T.E. Simina, L.P. Malova, O.N. Loginov, Theory and practice of physical culture, 6, 50-51 (2019)

12. V.A. Martynova, Modern Applied Science, 8(6), 306-312 (2014)

13. V.A. Martynova, A.G. Kapustin, International Journal of Environmental and Science Education, 11(13), 6041-6055 (2016)

14. R.M. Saitov, T.S. Lisitskaya, Theory and practice of physical culture, 12, 99-104 (2013) 